\title{
PEMBUATAN SPESIMEN AWETAN ORGANISME UNTUK MENUNJANG PELAJARAN KEANEKARAGAMAN HAYATI DI SEKOLAH
}

Yuliadi Zamroni ${ }^{1 *}$, Galuh Tresnani ${ }^{1}$, Bambang Fajar Suryadi ${ }^{1}$, Dining Aidil Candri1 dan Sukiman ${ }^{1}$

${ }^{1}$ Fakultas Matematika dan Ilmu Pengetahuan Alam Universitas Mataram *Co-Author : yzamroni@unram.ac.id

\begin{abstract}
ABSTRAK. Telah dilakukan pelatihan pembuatan spesimen awetan organisme kepada guru-guru di provinsi NTB. Kegiatan ini bertujuan untuk meningkatkan keterampilan guru dalam membuat media pembelajaran untuk menunjang pelajaran keanekaragaman hayati disekolah. Kegiatan ini dilakukan selama 4 hari dari tanggal 30 Oktober-2 November 2017 yang diikuti oleh 34 guru yang ada di NTB. Melalui kegiatan ini, para guru diperkenalkan tentang keanekaragaman hayati yang ada di NTB khususnya dan Indonesia pada umumnya. Selain itu para guru juga dilatih melakukan sampling dan pengawetan flora dan fauna yang ada disekitar lingkungan tempat tinggal. Tehnik fotografi dan manajemen spesimen awetan diberikan untuk menambah softskill para guru sehingga spesimen yang dikoleksi dapat disimpan dalam jangka waktu yang lama. Para peserta pelatihan memberikan respon yang positif terhadap kegiatan ini. Hal tersebut dapat diketahui melalui jumlah peserta yang melebihi target, antusiaisme dalam mengikuti setiap kegiaatan dan permintaan untuk diundang dalam pelatihan-pelatihan berikutnya yang diadakan Universitas Mataram.
\end{abstract}

Kata Kunci: Herbarium, insektarium, awetan basah, awetan kering, rangka

ABSTRACT. There has been a specimen of the preservation of organism for the teachers in NTB province. This activity aims to improve the skills of teachers in making media learning to support biological diversity lessons in a school. This activity was conducted for 4 days from October 30 th to November 2nd, 2017 followed by 34 teachers in NTB. Through this activity, teachers were introduced about the biodiversity that exists in NTB in particular and Indonesia in general. In addition, the teachers were also trained to perform sampling and preservation of existing flora and fauna around the neighborhood. Photographic techniques and specimen management were given to enhance the softskill of the teachers so that the collected specimens can be stored for long periods of time. The trainees respond positively to this activity. It can be known by the number of participants who exceed the target, antusiaisme in following each activity and request to be invited in the subsequent trainings held by the University of Mataram.



\section{PENDAHULUAN}

Indonesia merupakan salah satu negara megabiodiversitas dengan tingkat keanekaragaman hayati tertinggi di dunia. Indonesia memiliki berbagai macam tipe ekosistem, mulai dari padang salju di puncak Jaya Wijaya, pegunungan, hutan dataran rendah, padang rumput, savana, muara dan pesisir pantai, hutan mangrove, padang lamun, terumbu karang hingga perairan laut dalam. Keanekaragaman hayati Indonesia meliputi 12\% mamalia (515 spesies, 39 endemik), 7\% reptil (511 spesies, 150 endemik) dan 17\% burung (1531 spesies, 397 endemik)yang dimiliki dunia, selain itu terdapat 270 spesies amfibi (100 endemik) dan 2.827 spesies binatang tidak bertulang belakang (Indrawan dkk, 2007). Monk dkk. (2000) mencatat pulau Lombok di provinsi Nusa Tenggara Barat (NTB) memiliki 26 spesies tumbuhan endemik, 25 spesies capung, 17 spesies belalang, 14 spesies kupu-kupu famili Papilionidae, 31 spesies ikan air tawar, 11 spesies amphibian, 49 spesies reptil, 172 spesies burung dan 71 spesies mamalia. Catatan terbaru melaporkan ekosistem mangrove Teluk Lembar kabupaten Lombok Barat memiliki 31 spesies ikan dari famili Gobiidae (Zamroni et al. 2016).

Tingginya tingkat keanekaragaman hayati yang dimiliki Indonesia harusnya dapat menjadikan ekosistem yang dekat dengan kehidupan seperti sawah, kebun dan lapangan sebagai laboratorium untuk mempelajari keanekaragaman hayati 
sejak usia dini. Namun, pengenalan tentang keanekaragaman hayati dilingkungan sekitar tempat tinggal/sekolah masih sangat rendah. Salah satu contoh nyata adalah buku-buku pelajaran di sekolah sering kali menggunakan contoh-contoh hewan dari mancanegara, seperti burung unta, beruang kutub, dan jerapah. Hanya sebagian kecil saja yang menggunakan contoh-contoh makhluk hidup dari lingkungan di sekitarnya. Hal ini diduga menjadi salah satu penyebab tidak pedulinya masyarakat akan pentingnya manfaat keanekaragaman hayati di sekitarnya.

Pembelajaran tentang keanekaragaman hayati di Indonesia saat ini telah tercantum dalam kurikulum mata pelajaran sains biologisekolah tingat SMP dan SMU dengan kompetensi dasar antara lain dapat mendeskripsikan konsep keanekaragaman gen, jenis, dan ekosistem melalui kegiatan pengamatan,dapat mengkomunikasikan keanekaragaman hayati Indonesia dan dapat melakukan usaha pelestarian serta pemanfaatan sumber daya alam (Leksono et al. 2013).Pembelajaran sains biologihendaknya mengutamakan pemberian pengalaman secara langsung kepada siswa sedangkanguru hanya bertindak sebagai fasilitator. Melalui hal tersebut diharapkan dapat membuat siswa mengembangkan berbagai keterampilan yang dimiliki untuk mendapatkan hasil belajar yang maksimal. Permasalahan yang sering muncul adalah umumnya model pembelajaran yang diberikan dikelas hanya satu arah dimana guru sebagai pusat aktivitas sedangkan siswa hanya mendengarkan secara pasif sehingga kemampuan berpikir siswa menjadi kurang berkembang. Guru kurang memanfaatkan lingkungan sekitar dan laboratorium sebagai media dan sumber pembelajaran yang dapat memberikan pengalaman nyata kepada siswa untuk memahami konsep-konsep dalam sains biologi khususnya materi keanekaragaman hayati yang ada disekitarnya (Sanjaya 2006).

Pembuatan spesimen organisme adalah salah satu sumber utama dalam mepelajari keanekaragman hayati yang ada dilingkungan sekitar. Agar siswa dapat merasa memiliki, memahami dan menjaga keanekaragaman hayati yang ada di daerahnya, maka pembelajaran konservasi keanekaragaman hayati tidak akan cukup hanya dengan mempelajari teoriteori konservasi didalam kelas. Siswa perlu diajak mengenal keanekaragaman hayati tersebut di habitat aslinya, oleh sebab itu guruperlu memiliki pengetahuan dan keterampilan tentang cara mengkoleksi dan mengawetkan organisme agar dapat dijadikan materi pembelajaran di laboratorium. Setiap jenis organisme memiliki karakteristik berbeda, sehingga terdapat variasi cara koleksi, metode fiksasi dan pengawetan setiap organisme berdasarkan karakteristiknya. Oleh sebab itu, pengabdian kepada masyarakat ini penting dilakukan agar gurumemiliki keterampilan dalam membuat spesimen awetan organisme dan memanajemen laboratorium sehingga pembelajaran keanekaragaman hayati dikelas menjadi lebih nyata.

\section{ANALISIS PERMASALAHAN}

Permasalahan utama yang dijumpai dalam kegiatan ini adalah kurangnya kesadaran guru akan manfaat lingkungan sekitar sebagai laboratorium lapangan serta kurangnya bahan ajar yang dimiliki guru-guru dalam mempelajari keanekaragaman hayati lokal.

\section{SOLUSI YANG DITAWARKAN}

Permasalah ini dipecahkan melalui serangkaian kegiatan pengabdian kepada masyarakat yang terdiri dari beberapa tahap kegiatan antara lain pengenalan keanekaragaman hayati yang ada di NTB khususnya dan Indonesia pada umumnya dengan menunjukkan koleksi spesimen flora dan fauna yang dimiliki Laboratorium Biologi, Fakultas MIPA, Universitas Mataram.

Kurangnya bahan ajar yang dimiliki guru-guru dalam mempelajari keanekaragaman hayati lokal dipecahkan dengan cara guru diajak praktek secara langsung metode sampling hewan dan tumbuhan di sekitar Universitas Mataram kemudian dilanjutkan dengan pelatihan pembuatan spesimen awetan basah, awetan kering, awetan rangka, insektarium danherbarium yang didasarkan pada spesimen yang telah dikoleksi. Selain itu, guru-guru juga dilatih mengidentifikasi organisme yang di koleksi, tehnik pengambilan gambar/foto dan manajemen spesimen koleksi agar spesimen awetan 
yang dikoleksi dapat bertahan untuk penyimpanan dalam jangka waktu yang lama. Kegiatan pengabdian ini dilakukan selama 4 hari mulai tanggal 30 Oktober-2 November 2017 di Laboratorium Biologi FMIPA Universitas Mataram dengan melibatkan guru-guru SMP/MTs dan SMA/MA di provinsi NTB.

\section{HASIL DAN PEMBAHASAN}

Kegiatan pengabdian kepada masyarakat ini diikuti oleh 34 guru SMP/MTs dan SMA/MA seprovinsi NTB meliputi 6 guru dari Sumbawa, 4 guru dari Kota Mataram, 2 guru dari Kabupaten Lombok Tengah dan 22 guru dari Kabupaten Lombok Barat. Kegiatan pengabdian diawali dengan pengenalan potensi keanekaragaman hayati yang dimiliki oleh provinsi NTB melalui diskusi tentang hasil-hasil riset keanekaragaman organisme NTB, temuan-temuan spesies endemik yang hanya ditemukan di NTB atau Kepulauan Nusa Tenggara serta menunjukkan koleksi flora dan fauna yang ada di Laboratorium Biologi FMIPA Universitas Mataram. Pada tahap ini, sebenarnya guru-guru telah mengetahui keanekaragaman jenis flora dan fauna yang ada NTB tetapi pengetahuan tersebut hanya bersifat umum seperti rusa, kupu-kupu, capung, belalang dan hewan-hewan umum yang mudah ditemukan setiap hari. Setelah melihat secara detail spesimen koleksi yang ada di Laboratorium Biologi FMIPA Universitas Mataram, barulah disadari tentang tingginya keanekaragaman jenis kupu-kupu, belalang, ikan air tawar dan berbagai jenis flora dan fauna yang ada di NTB.

Kegiatan berikutnya dilakukan pembekalan tentang tehnik sampling flora dan fauna serta berbagai macam metode pengawetan organisme khususnya tehnik pembuatan awetan basah hewan, tehnik pembuatan awetan kering hewan, tehnik pembuatan awetan rangka, insektarium dan herbarium. Setelah pembekalan secara teoritik, Bapaklibu guru kemudian diajak untuk praktek melakukan sampling flora dan fauna yang ada disekitar Universitas Mataram (Gambar 1). Melibatkan guru untuk melakukan sampling bertujuan untuk memperkenalkan kepada bapak/ibu guru bahwa materi keanekaragaman hayati ada dan melimpah disekitar lingkungan tempat tinggal. Spesimen yang dikoleksi kemudian diawetkan, tehnik pengawetan bervariasi disesuikan dengan jenis flora dan fauna yang dikoleksi dan tujuan dari masingmasing pengawetan organisme (Gambar 2). Guru peserta pelatihan tampak antusias mengikuti setiap kegiatan sampling ataupun pengawetan organisme, hal ini disebabkan karena melalui kegiatan tersebut para guru menyegarkan ingatan kembali tentang masa-masa tugas akhir saat menyelesaikan kuliah jenjang sarjana (S1).

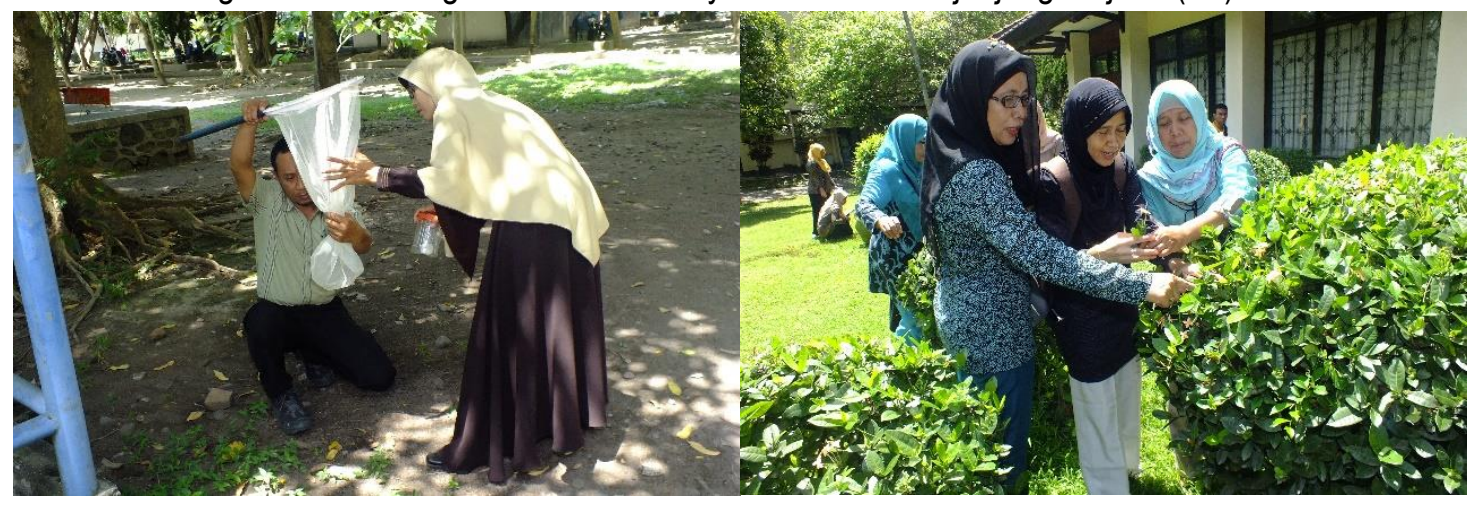

A

B

Gambar 1. Peserta pelatihan melakukan sampling organisme disekitar Universitas Mataram. (A) Sampling hewan; (B) Sampling Tumbuhan. 




Gambar 2. Peserta pelatihan melakukan praktek pembuatan herbarium dan insektarium

Seringkali spesimen organisme yang telah diawetkan mengalami pemudaran warna serta mudah rusak dan membusuk. Berdasarkan hal tersebut, melalui kegiatan pengabdian kepada masyarakat ini para guru dilatih untuk mengambil gambar/foto spesimen sebelum pengawetan dilakukan (Gambar 3). Foto hidup spesimen akan sangat membantu dalam mengidentifikasi organisme yang baru ditangkap dan membandingkan perubahan yang dialaminya setelah pengawetan. Selain itu, para guru juga dibekali tentang manajemen perawatan spesimen agar spesimen yang telah dikoleksi tidak cepat membusuk dan dapat bertahan sebagai media pembelajaran dalam jangka waktu yang lama. Menjaga koleksi spesimen menjadi sangat penting karena kita harus dapat menjaga kelestarian flora dan fauna yang ada di alam. Dengan adanya spesimen awetan, maka guru/siswa tidak harus selalu menangkap spesimen segar untuk dipelajari. Selain itu spesimen yang sudah didapatkan belum tentu dapat ditemukan kembali saat sampling berikutnya. Berdasarkan hal ini, manajemen koleksi spesimen menjadi sangat penting dalam konservasi.

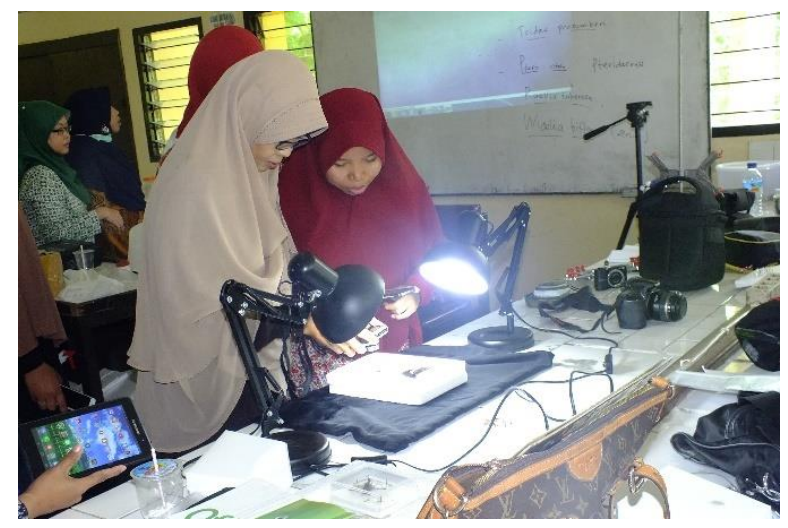

Gambar 3. Peserta pelatihan melakukan praktek fotografi

Berdasarkan hasil kegiatan pengabdian kepada masyarakat yang telah dilakukan, kegiatan ini mendapat respon dan apresiasi positif dari para guru peserta pelatihan. Hal ini dapat dilihat dari membeludaknya peserta kegiatan. Pada awalnya peserta kegiatan ditargetkan sebanyak 20 peserta yang rencananya berasal dari Kota Mataram dan sekitarnya, tetapi saat kegiatan berlangsung jumlah peserta mencapai 34 orang yang berasal dari Sumbawa, Kota Mataram, Kabupaten Lombok Barat dan Kabupaten Lombok Tengah. Respon positif ini juga dapat dilihat dari antusiasnya para peserta mengikuti setiap kegiatan selama 4 hari dan adanya permintaan dari peserta agar Universitas Mataram melakukan pelatihan-pelatihan kepada guru dalam tema-tema biologi lainnya atau bahkan ilmu sains yang lainnya. Melalui kegiatan pengabdian ini softskill para guru diasah kembali agar dapat menyampaikan materi sains di sekolah dengan lebih melibatkan peran aktif siswa dalam pembelajaran di kelas/laboratorium. 


\section{KESIMPULAN}

Kegiatan pengabdian pada masyarakat ini merupakan kegiatan yang sangat bermanfaat dan menambah keterampilan guru-guru dalam mengajarkan materi keanekaragaman hayati di sekolah. Pendekatan yang dilakukan dengan melibatkan langsung para guru dalam mengoleksi spesimen dan mengawetkannya mampu meningkatkan antusiaisme dan semangat guru dalam mengikuti kegiatan sampai akhir kegiatan.

\section{UCAPAN TERIMA KASIH}

Tim Pelaksana Pengabdian Kepada Masyarakat mengucapkan terima kasih kepada Universitas Mataram atas bantuan dana yang diberikan dalam kegiatan pengabdian ini. Kegiatan ini dibiayai dari sumber dana DIPA BLU (PNBP) Universitas Mataram tahun anggaran 2017 dengan surat perjanjian pelaksanaan kegiatan Nomor : 608/UN18/LPPM/2017. Selain itu, tim pengabdian juga mengucapkan terima kasih kepada Ni Made Sudewianingsih dan Dwi Ampera Hananto sebagai laboran di Laboratorium Biologi FMIPA Unram atas batuan yang diberikan. Ucapan terima kasih juga disampaikan kepada Kusumawardani, Marliana, Muh. Andhi Hardianto, Rizqi Adekayanti Putri dan Zulkaidah Wati atas batuannya mendampingi peserta pelatihan dalam sampling dan praktek pembuatan spesimen

\section{REFERENSI}

Indrawan, M., Primack, R.B. dan Supriatna, J. 2007. Biologi Konservasi. Jakarta: YayasanObor.

Leksono, S.M., Rustaman, N., Redjeki S. 2013. Kemampuan Provesional Guru Biologi dalam Memahami dan Merancang Model Pembelajaran Konservasi Biodiversitas di SMA. Cakrawala Pendidikan 32 (3): 408-419.

Monk K.A., de Fretesi Y., Reksodihardjo-Lilley G. 2000. Ekologi Nusa Tenggara dan Maluku: Seri Ekologi Indonesia Buku V. Prenhallindo, Jakarta.

Sanjaya W. 2006. Strategi Pembelajaran. Jakarta : Kencana Prenada Media.

Zamroni Y., Soewardi K., Suryobroto B., Jaafar Z. 2016. Short Communication: Conservation of Mangrove Gobies in Lesser Sunda Islands, Indonesia. Biodiversitas 17(2): 553-557. 